\title{
Notas sobre la concordia en Apolonio de Rodas ${ }^{1}$
}

\author{
Álvaro Cancela Cilleruelo \\ alvarocancela@yahoo.es
}

Recibido: 18 de enero de 2010

Aceptado: 30 de diciembre de 2010

\begin{abstract}
RESUMEN
El artículo trata el motivo de la concordia dentro de las Argonáuticas de Apolonio de Rodas, relacionando su presencia con otros temas afines y recurrentes. El objetivo básico es destacar su variada y constante aparición a lo largo de todo el poema, prestando especial atención al libro cuarto. Se sugiere asimismo vincular la concordia en las Argonáuticas con las teorías aristotélicas contenidas en la Et. Nic. y Et. Eud.
\end{abstract}

Palabras clave: Apolonio de Rodas, Argonáuticas, Jasón, concordia.

\begin{abstract}
This paper deals with the concord as a topic in the Argonautica of Apollonius Rhodius, relating it with other associated and recurring themes. The essential aim is to stress its varied and constant presence in the whole poem, paying attention to the fourth book especially. It is also suggested that the concord in the Argonautica could be connected to the Aristotelian theories from Eth. Nic. and Eth. Eud.
\end{abstract}

Key words: Apollonius Rhodius, Argonautica, Jason, concord, social harmony.

\section{INTRODUCCIÓN}

La importancia de la concordia en las Argonáuticas ya fue advertida en 1974 por Francis Vian, quien señalaba en ella «un tema esencial, por lo menos en los tres primeros libros» ${ }^{2}$. Sin embargo, al tomar en consideración la obra en su integridad, la presencia del motivo de la homónoia bien podría hacerse extensible también al libro cuarto, y con él a todo el poema; desde esta perspectiva, la concordia aparece en los tres primeros cantos como un valor que los argonautas se afanan por lograr y conservar, mientras en el cuarto es una conquista ya consumada de la expedición. Con ello se asegura la continuidad del motivo a lo largo de la obra ${ }^{3}$.

Tomando, pues, como punto de partida las apreciaciones de Vian, pero enjuiciando

\footnotetext{
${ }^{1}$ Conste ante todo mi agradecimiento a la Dra. Mercedes López Salvá, por su paciente y generosa dirección y sus atinadas observaciones.

${ }^{2}$ Vian (1974a: 349). Véase también Vian (1974b: 15-17, 48-49, 124) y el trabajo de Mori, cit. en la n. 72.

${ }^{3}$ Sobre lo cual, $c f r$. el epígrafe 6 . Conclusiones.
} 
el poema en su totalidad, se pretende espigar y reunir las diversas manifestaciones, nucleares y periféricas, del motivo de la concordia en las Argonáuticas ${ }^{4}$ : la consideración del viaje como empresa conjunta, la toma democrática de decisiones, la figura de Jasón como valedor del grupo y la homónoia, la constante colaboración entre los expedicionarios, la actuación y el sentir colectivos, la solución provechosa de los conflictos internos y la admisión de nuevos compañeros. Para concluir, se sugiere relacionar la presencia de la concordia en la obra de Apolonio con las tesis aristotélicas contenidas en las Et. Nic. y Et. Eud., en la línea de los trabajos de A. Mori y R. Hunter.

\section{EL QUEHACER COMPARTIDO DE LOS ARGONAUTAS}

El carácter colectivo de la leyenda de los argonautas remonta, al menos, hasta la constitución del mito ${ }^{5}$. Apolonio lo convierte en un motivo recurrente en su obra (el viaje como quehacer compartido) y su reiterada aparición contribuye a la unidad temática del poema.

Tanto en el inicio de la obra como en su conclusión es manifiesto el tema de la epopeya colectiva: el poema no principia con la figura de Jasón, sino con las «hazañas de hombres de antigua estirpe» y "el linaje y el nombre de los héroes, las rutas del anchuroso mar y cuanto llevaron a cabo errantes», concluyendo igualmente con una súplica al grupo: «sedme favorables, estirpe de héroes dichosos». Conforme a ello, pues, no sorprende que en la obra el protagonismo no se reduzca a Jasón y se distribuya entre la tripulación escena tras escena, ya a modo de acción colectiva, ya como actuación individual por parte de alguno de los héroes. De hecho, de los cincuenta y cuatro héroes de que consta el catálogo del libro primero (I 23-233), bastantes más de la mitad aparecerán de nuevo en algún momento de la obra, y algunos de ellos desempeñarán papeles verdaderamente destacados: tal el caso de Orfeo, Heracles, Telamón, Idmón, Idas, Peleo, Cástor y Polideuces, Zetes y Cálais, Eufemo, Mopso o Tifis. La propia compañía de argonautas actúa, pues, como un tema literario más en Apolonio ${ }^{7}$.

\footnotetext{
${ }^{4}$ Para el texto de las Argonáuticas citamos y traducimos la edición de Vian (1974b, 1980 y 1981), consultando también las de Mooney (1912), Seaton (1967), Fränkel (1961) y Livrea (1973), dedicada al libro cuarto. Hay cuatro traducciones modernas al español, debidas a García Gual (1975, reimpr. 2004), Brioso (2003³), Pérez L. (1991) y Valverde (1996). Para las versiones extranjeras, cfr. Seaton (1967), Rieu (1959), Vian y Delage (1974b, 1980, 1981), Paduano (2000 ${ }^{12}$ ) y Green (2007).

${ }^{5}$ Sobre el origen y constitución del mito de los argonautas, $c f r$. breve síntesis en Llinares (1987: 21-4) y Valverde (1996: 20-3), con referencia a los trabajos clásicos de Meuli y Radermacher; para un análisis del mito de Jasón y Medea, $c f r$. el libro de Moreau (1994, esp. pp. 23-80).

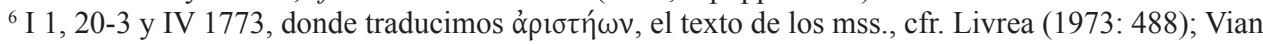

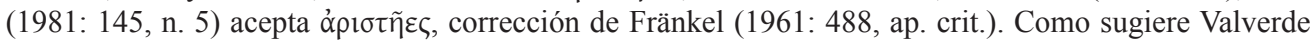
(1988: 128-32), compárese el proemio y epílogo de las Argonáuticas con el inicio de la Odisea (Od. I 1) y la alocución de Atenea al término de la obra («iLaertíada, prosapia de Zeus, Odiseo, fecundo en ardides!» en Od. XXIX 542-5). Cfr. también Clauss (1993: 62).

${ }^{7}$ Cfr. Valverde (1988: 128 y ss.). Sobre el motivo de la actuación colectiva $c f r$. infra, el epígrafe 3. Colaboración y camaradería en la expedición. A este respecto, ya Wilamowitz (1924: 215) y Carspecken
} 
El poeta presenta desde el principio un valor cívico fundamental en el poema, una suerte de conciencia de comunidad por la que los argonautas toman partido decididamente y que impregna la obra por entero: la concordia. Efectivamente, pronto el lector advierte que los propios argonautas tienen plena conciencia del carácter colectivo de su empresa, de su unidad como grupo, y en suma, de que, presa de la necesidad, la suerte de uno es la de todos. Apenas iniciado el poema, en la escena de Págasas Jasón llama a sus compañeros para que elijan libremente un capitán, apelando ya a un cierto espíritu democrático que reaparecerá a lo largo de toda la obra (I 336-340):

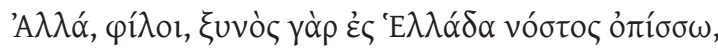

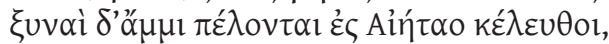

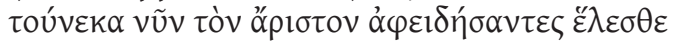

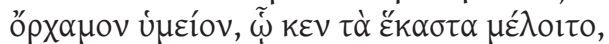

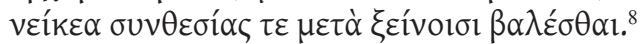

La convicción de que por ser comunes las circunstancias del viaje y del regreso, comunes han de ser las decisiones que se adopten, empapa totalmente la conciencia de los héroes en Apolonio. Cada determinación de alcance que hayan de tomar, si no es atendida en asamblea, la refrendan todos o una amplia mayoría con su aquiescencia, o al menos con su aceptación'. Por ello precisamente la elección del jefe es una escena muy ilustrativa en el conjunto del poema: aunque los héroes eligen como capitán a Heracles, éste nombra jefe a Jasón por haberlos reunido; pese a ser una imposición, los argonautas otorgan su asentimiento y acuerdan confiar a Tifis el timón ${ }^{10}$. Sin embargo, y en contraste con el heroísmo tradicional, Jasón no va a desempeñar en ningún momento el papel de líder absoluto; más bien procederá, al decir de Wilamowitz, como un primus inter pares, sometiendo al juicio mayoritario las decisiones que haya de adoptar y promoviendo la unidad y solidaridad mutua entre los compañeros: el Jasón de Apolonio, como podrá advertirse en esta colección de parlamentos, actúa como un auténtico valedor de la homónoia argonáutica ${ }^{11}$.

(1952) subrayaron hasta tal punto esta perspectiva que llegaron a considerar al grupo en su conjunto como el verdadero héroe del poema. Cfr. críticas tanto en Phinney (1964: 77), para quien la función principal del grupo de argonautas no es la de protagonista, sino ejercer de «coro» en el poema, como en Clauss (1993: 62, n. 10), que ve en ello una exageración. En cuanto a la presencia de este motivo en la tradición, se ha señalado que el tratamiento de los argonautas como un grupo de $v \varepsilon ́$ or en Apolonio, a despecho de sus diferencias de edad, tal vez sea un resto de un estadio anterior del mito en el que todos los argonautas eran кoÚpor de la misma edad; en este línea opina Vian, cit. por Moreau (1994: 120): «s'il n’en est plus ainsi chez Apollonios, chacun sait que les Argonautes constituent une société égalitaire, d'où toute hiérarchie est bannie». El mito se ha analizado en este sentido como un rito iniciatorio, de paso de la juventud a la edad adulta; $c f r$. Llinares (1987) y Moreau (1994: 117-42).

${ }^{8}$ «Pero, amigos, pues común es el regreso a la Hélade en el porvenir y comunes para nosotros son las rutas hacia el reino de Eetes, por ello ahora elegid sin contemplaciones al mejor de vosotros como líder, a cuyo cuidado quede cada asunto, encargarse de las querellas y los convenios con los extranjeros.»

${ }^{9}$ Al respecto Phinney (1964: 75-7) señala además cómo las lemnias, al igual que los argonautas, se reúnen también en asamblea (I 653 y ss.).

${ }^{10}$ I 332-401. Cfr. Clauss (1993:61-6).

${ }^{11}$ Wilamowitz (1924: 215), cit. por Valverde (1988: 131). Igualmente Fränkel (1968: 243): «Der 
A este respecto, los sucesos ocurridos tras el fallecimiento de Tifis son muy ilustrativos: se trata ante todo de preservar la concordia ${ }^{12}$. Cuando la muerte del timonel con el que habían sorteado las Simplégades abate completamente a la tripulación, Hera da fuerzas a Anceo para proponerse para el puesto de piloto; éste, sin embargo, no se presenta abiertamente ante sus compañeros, ni mucho menos ante el apenado Jasón (lo cual, dado el desánimo general, hubiera resultado poco conveniente); prefiere hablar a solas con Peleo, sugerirse para el puesto y añadir que, en todo caso, hay en la nave varios compañeros que podrían bien guiar la nave, de ser necesario. Peleo entonces se dirige al grupo, repitiendo básicamente las palabras de Anceo sin nombrarlo personalmente. En vista de la situación, y precisamente para provocar el amor propio de algún compañero capacitado, Jasón decide poner a prueba a sus compañeros sometiéndolos a una nueva peîra, y asegura que los posibles timoneles que puedan encontrarse allí están, por lo que parece, más abatidos que él mismo ${ }^{13}$. La maniobra psicológica de Jasón tiene éxito, se salva el brete y, con él, la concordia: el propio Anceo, impelido de nuevo por Hera, se propone ante todos para el puesto, y la mayoría de sus compañeros lo ratifican, conteniendo a tres nuevos candidatos ${ }^{14}$.

En este mismo orden se sitúa sin duda el discurso de Jasón al arribar a Ea, cuando al tratar el modo de presentarse a Eetes, comienza recordando a la expedición la naturaleza colectiva de su empresa y su confianza en la voluntad de la mayoría (III 171-175):

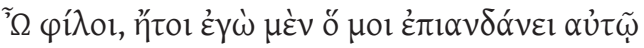

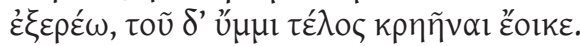

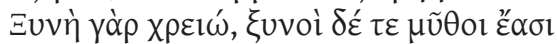

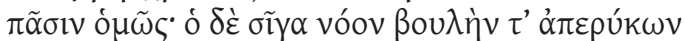

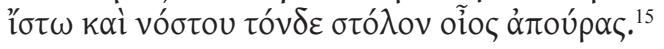

Su propuesta una vez más será aprobada por la expedición. Los ejemplos de este comportamiento democrático por parte de los argonautas recorren el poema sin solución de continuidad de inicio a fin ${ }^{16}$. De entre todos ellos destacaremos uno, casi al

Jason des Ap. fühlte sich nur als primus inter pares, und er ging in allen wichtigen Fragen gut demokratisch zu Werke». También Hunter (1993: 24-5) destaca este rasgo característico del heroísmo del Jasón de Apolonio en oposición al comportamiento del Odiseo homérico.

${ }^{12}$ Así literalmente Vian (1974a: 349 y 1974b: 279). Cfr. Fränkel (1968: 239-43) y Levin (1971: 190-4).

${ }^{13}$ Es la segunda vez que Jasón obra de este modo; la primera peîra, que prefigura esta, había tenido lugar en II 622-37. Cfr. Fränkel (1968: 214-9). Hunter (1988: 447-8), en cambio, aunque no está en total desacuerdo con esta lectura de Fränkel y Vian, considera determinante la intervención de Hera, objetando que el énfasis puesto por ambos en la conducta humana nace de perspectivas modernas y por lo tanto anacrónicas.

${ }^{14} C f r$. toda la escena en II 864-98.

15 «Amigos, yo, desde luego, voy a decir abiertamente lo que a mí mismo me place, pero a vosotros os cuadra dar a ello cumplimiento. Pues común es la necesidad y comunes son las palabras para todos igualmente; y el que calle, retirando su razón y consejo, sepa que también le roba el regreso, él solo, a esta expedición.»

${ }^{16}$ Cfr., junto con lo ya citado, la aprobación que dan al plan de Anfidamante para deshacerse de las aves en II 1047-79; el asenso a propósito de la propuesta de Mopso en III 506-76; la nueva puesta en 
término, en el cual Jasón, tras el desastre de la nave, reúne de nuevo a sus compañeros, perdidos por el desierto africano, para compartir con ellos el prodigio que se le ha aparecido -tres diosas locales, protectoras de Libia-y examinar juntos sus palabras, en busca de indicios para el regreso. Un hombre solo no comprende enteramente y Jasón, al despedirse de las divinidades, prefiere confiar en el discernimiento de la mayoría (IV 1333-1336):

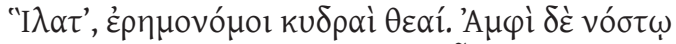

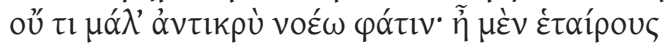

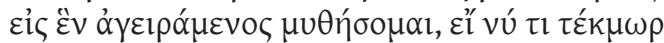

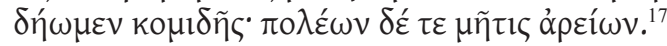

\section{COLABORACIÓN Y CAMARADERÍA EN LA EXPEDICIÓN}

Convencidos de que su empresa es colectiva y su suerte común, la amistad, la concordia y la avenencia con que adoptan cada acuerdo y que tanto tutela Jasón quedan bien urdidas en una trama mayor de relaciones de sympátheia, camaradería y colaboración.

Los argonautas sienten como grupo, compartiendo regocijos, arrebatos, conmociones y penalidades: alegría y tristeza cunden alternativamente entre los héroes con las profecías de Idmón, apenas llegados a Yolco ${ }^{18}$. Se llenan de satisfacción al saber la verdadera suerte de los héroes abandonados, al arribar a tierras feacias y al conocer la decisión de Alcínoo respecto de Medea ${ }^{19}$. No ocultan su cólera ante las amenazas de Ámico, se duelen al oír el relato de Fineo y animan a Jasón cuando finge desolación ante ellos ${ }^{20}$. Abatidos por la muerte de Idmón, quedan tan consternados con la de Tifis que rechazan comer y beber, tal como harán de nuevo en las hediondas aguas del Erídano ${ }^{21}$. También sufrirán al dejar atrás a las sirenas y acercarse a Escila y Caribdis, y especialmente en el pasaje del desierto de Libia, tras el desastre de la $\mathrm{Argo}^{22}$. Frente a los toros de Eetes los héroes se pasman, tal como al contemplar el vellón por vez primera, al escuchar los bramidos de la Argo, al avistar a Circe y al escuchar el relato de Jasón sobre las diosas de Libia ${ }^{23}$.

De igual modo que deciden en grupo y en consenso, así también actúan, ya desde

\footnotetext{
práctica, a sugerencia de Jasón, del plan de Anfidamante para esquivar a Eetes en Ea en IV 190-206; la aceptación, previa señal divina, de la proposición de Argos para una nueva ruta de regreso en IV 257-300; y el plan de Peleo para despistar en su huida a las tropas de los colcos en IV 495-502.

${ }_{17}$ «iSed propicias, pobladoras del desierto, ilustres diosas! En cuanto al regreso, no comprendo enteramente vuestro augurio; mas de cierto que, reuniendo en grupo a mis compañeros, se lo referiré, por si alguna señal hallamos de retorno; que es mejor el pensamiento de muchos.» La superioridad de la actuación colectiva aparece ya en Homero (Il. X 224-6, o Il. XII 412). Cfr. Livrea (1973: 377).

${ }^{18}$ I 448-9.

${ }^{19}$ I 1339 , IV 999-1000 y IV 1126-7.

${ }^{20}$ II $19-20$, II 240 y II 620-46.

${ }^{21}$ II 815 y ss., II 851 y ss. y IV 619-20.

${ }^{22}$ IV 920 y IV 1225 y ss.

${ }^{23}$ III 1293, IV 184, IV 584-5, IV 682, IV 1363.
} 
la botadura común de la nave en la costa de Págasas ${ }^{24}$ : puede citarse la puesta en práctica del plan de Anfidamante contra las aves de Ares, o la escapada en aguas del Fasis -ambas antes aludidas-, o la ayuda que prestan Cástor y Pólux a Jasón, tras acordarlo con él, al acercarle el yugo que habría de uncir a los toros, o el traslado del navío a hombros por el desierto durante doce días sin viandas ${ }^{25}$. Por otra parte, bajo esta concepción todos los acontecimientos de la Cólquide bien podrían considerarse, tal como sostiene Levin, un ejercicio en colaboración, en el que toman parte no ya sólo Jasón y los argonautas, sino también los cuatro hijos de Frixo, Medea, Fineo con sus profecías y las divinidades protectoras de la expedición ${ }^{26}$.

Las competiciones que celebran son también un ejercicio de camaradería y provecho para el bien común: disputar qué varón se cansará en último lugar de remar, lanzar discos y flechas en una ensenada, o competir «en disputa sin tacha» (IV 1767) por ver quién regresa primero a la nave de ir a recoger agua ${ }^{27}$. No se privan, en el feliz clima del retorno, ni de reírse con las burlas que les dirigen las esclavas feacias ni de hacer con ellas bromas jocosas y descaradas ${ }^{28}$.

Es también muy significativo a este propósito que toda escena de combate en la obra tenga siempre cierta impronta colectiva ${ }^{29}$. En uno de los primeros encuentros, Heracles y unos pocos se enfrentan a los terrígenos y rápidamente se unen los demás ${ }^{30}$. El duelo entre Polideuces y Ámico no supone de ningún modo una excepción: el tindárida acepta la lucha «como paladín de sus compañeros» (II 21), y al dar muerte a Ámico y caer sobre él todos los bébrices, los argonautas toman las armas para defender a su camarada $^{31}$. Juntos responden a las llamadas de auxilio de Idmón, atacado y muerto por un jabalí al que hiere Peleo y remata Idas, y juntos también acabarán con Cafauro, el pastor que había sorprendido y dado muerte al argonauta Canto cuando éste pretendía robarle el hato para llevárselo «a sus necesitados compañeros» (IV 1487-9) ${ }^{32}$. Tras el engaño perpetrado contra Apsirto, los héroes caen sobre la nave de éste masacrando a toda la tripulación; también en Feacia tomarán las armas juntos ante la cámara nupcial de Jasón y Medea, para precaverse de un eventual ataque enemigo ${ }^{33}$. Pudiérase decir que, aun cuando son cobardes - como frente a Talos-, lo son al menos todos a una ${ }^{34}$.

Por último, son destacables también las varias ocasiones en que los argonautas vierten juntos libaciones, celebran sacrificios o entonan himnos en honor de dioses o

\footnotetext{
${ }^{24}$ I 371 y ss.

${ }^{25}$ II 1047-68, IV 190-206, III 1314-6, IV 1382 y ss.

${ }^{26}$ Levin (1971: 58).

${ }^{27}$ I 1153-8, IV 851-2 y IV 1767-8. Para los paralelos en la literatura de esta competición amistosa, cfr. Livrea (1973: 482).

${ }^{28}$ IV 1725 y ss.

${ }^{29}$ Sobre las escenas de batalla en la obra $c f r$. Knight (1995: 82-121).

${ }^{30}$ I 989 y ss.

${ }^{31}$ II 98-144.

${ }^{32}$ II $823-32$ y IV 1485 y ss.

${ }^{33}$ IV 482, 1000 y 1155-60. Respecto de la interpretación del primer texto, Livrea (1973: 155) señala que «Ap. usa ä $\mu v \delta 1 \varsigma$ sempre col senso di 'insieme', mai con valore temporale», aportando loci similes en la obra. Para esta fusión de la temática guerrera y la nupcial en la literatura helenística, $c f r$ igualmente Livrea (1973: 375-6).

${ }^{34}$ IV 1649.
} 
compañeros de expedición. Así, a petición de Jasón los jóvenes, antes de partir, ofician sacrificios a Apolo y le elevan un altar ${ }^{35}$; tras la confusión en que dan muerte por error a Cízico, los héroes erigen un altar a Rea, bailando bajo la tutela de Orfeo para purificarse del crimen cometido ${ }^{36}$. Del mismo modo, una vez derrotados los bébrices, los argonautas celebran nuevos sacrificios, preparan un festín y cantan un himno de encomio a Polideuces, dirigidos, una vez más, por Orfeo. Ofrecen también libaciones y sacrificios por Esténelo el actórida, tal como harán de nuevo en compañía de los hijos de Frixo, una vez revelado su linaje común ${ }^{37}$. En el desenlace de su aventura los argonautas erigen sendos altares en honor de Atenea Minoida y Apolo Luminoso ${ }^{38}$.

\section{DESENCUENTROS Y RECONCILIACIONES}

Por más que las contiendas habidas en el seno de la tripulación parezcan enturbiar por momentos el clima de amistad y concierto generales, lo cierto es que, a la postre, la solución de tales altercados redunda para la tripulación en una concordia no ya meramente restaurada, sino acrecentada y afianzada paso a paso ${ }^{39}$. Este proceso se advierte con claridad en la evolución de los dos héroes más problemáticos: Heracles e Idas.

La compleja figura de Heracles encarna al héroe épico tradicional, antitético de Jasón y en gran medida del espíritu común de los argonautas: héroe de héroes, Heracles es el único rival que, por prestigio y autoridad, podría oponerse a Jasón, y de hecho sus críticas y mandatos son acatadas siempre y al punto por los argonautas ${ }^{40}$. Desde el punto de vista estético e ideológico, Heracles no se ajusta desde el principio a los parámetros de la obra y su presencia en ella podría obedecer a criterios dramáticos y no sólo al aval de la tradición mítica ${ }^{41}$. Su personaje, como se apuntó más arriba, es motivo de discordia ya desde la elección misma del jefe, cuando impone que sea Jasón quien los comande por haberlos reunido, en lugar de aceptar el democrático nombramiento de la tripulación, que lo designaba a él ${ }^{42}$. Igualmente crea malestar en Lemnos, por cuanto es él quien reúne a la tropa en asamblea y, en un párrafo cargado de ironía, recuerda a los héroes que su misión es traer de regreso el vellocino y no conocer la hospitalidad de las lemnias, llegando incluso a proponer el abandono de Jasón en compañía de Hipsípila y que cada cual regrese a su hogar; ningún argonauta se atreve a responder, nadie

${ }^{35}$ I $351-62$.

${ }^{36}$ I $1078-152$.

${ }^{37}$ II $921-30$ y 1168 y ss.

${ }^{38}$ IV $1690-3$ y $1714-18$.

${ }^{39}$ Vian (1974a: 349 y 1974b: 48-9) y Valverde (1988: 138).

${ }^{40}$ Vian (1947a: 349). Sobre la figura de Heracles, puede verse Palombi (1985), Hunter (1993: 25-36) y Clauss (1993). Por lo que hace a Jasón, Fränkel, Jackson, Vian, Mooney, Gillies, Klein, Lawall, Beye, Hunter, Clauss y otros más han estudiado su personaje bajo concepciones muy divergentes, desde héroe de amor a héroe demasiado humano, héroe de la necesidad, personaje frío e insípido, o antihéroe. Cfr. Fränkel (1960), Vian (1980: 32-8), Jackson (1992), Clauss (1993) o Hunter (1988) y (1993: 15-25). Para un repertorio bibliográfico general puede consultarse Jackson (1992: 161-2, n. 1-9) y Vian, ibíd.

${ }^{41}$ Ya en la amplia mayoría de las versiones del mito Heracles no llegaba a Ea; en las menos no llegaba siquiera a participar en la expedición. Cfr. referencias en Clauss (1993: 176 y n. 1).

${ }^{42}$ I $327-49$. 
quiere ni mirarlo; apenas disuelta la asamblea ya se prepara la partida de Lemnos ${ }^{43}$. Así las cosas, con el célebre abandono de Heracles en Misia los héroes dejan atrás a un argonauta radicalmente opuesto a Jasón, dotado del suficiente prestigio y fuerza física como para crear serios problemas en la expedición, ajeno al espíritu concorde y democrático de la comunidad y a todas luces incompatible con el futuro desarrollo de los acontecimientos en Ea; así los argonautas parten «alegres» (I 1279) de Misia, dejando allí a Heracles, Hilas y Polifemo, y el viento, elemento simbólico a lo largo del poema, sopla entonces con todo brío ${ }^{44}$.

Sin embargo, a la hora de encontrar un responsable de tal pérdida surgen odios, recelos y acusaciones ${ }^{45}$. Jasón, turbado e impotente, es víctima de las iras de Telamón, que lo acusa de haber tramado junto con los demás el abandono de Heracles, para evitar que le haga sombra en la Hélade ${ }^{46}$. Enfurecido, Telamón se abalanza sobre Tifis, el timonel, para hacerle volver atrás e intentar buscar a Heracles, pero Glauco se aparece en las aguas del mar y anuncia el buen destino final de los tres héroes perdidos: las aguas vuelven a su cauce y los héroes, merced al deus ex machina, recuperan la homónoia. Telamón se acerca al punto a Jasón y, tras tomarle la mano y besarla, reconoce haber obrado presa de la imprudencia y el dolor; Jasón acepta sus disculpas y eleva su actuación a conducta ejemplar (I 1337-1343):

\begin{tabular}{|c|}
\hline 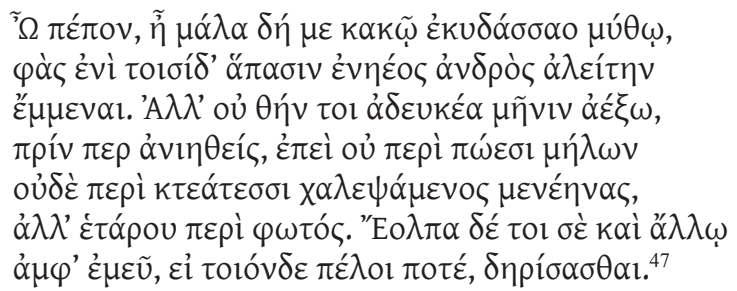 \\
\hline
\end{tabular}

Por último, si la marcha de un argonauta como Heracles y la solución de la disputa que se origina en el acto consolidan fuertemente la concordia en la expedición, la evocación del compañero perdido en diversas ocasiones a lo largo de la obra reafirma también el sentimiento de unidad del grupo. Así, tras el combate contra los bébrices los argonautas comentan cómo Heracles no hubiera dado ninguna oportunidad a Ámico y admiten que su pérdida fue un grave error que a la larga pagarán; pero todo ha sucedido por orden de Zeus, apostrofa el poeta ${ }^{48}$. En el encuentro con Lico, éste se duele de la

\footnotetext{
${ }^{43}$ I 869 y ss.

${ }^{44}$ I 1273 y ss. Sobre el abandono de Heracles, $c f r$. Clauss (1993: 176-211) y Levin (1971: 110-28).

${ }^{45}$ Sobre toda esta escena de reconciliación entre Jasón y Telamón, $c f r$. el trabajo de Mori (2005), que analiza el papel de la cólera en el poema con sus precedentes homéricos y sus presupuestos aristotélicos.

${ }^{46}$ I 1290 y ss.

47 «Amigo mío, de cierto que me has injuriado con palabras deshonrosas, al decir ante todos estos que soy culpable de lo sucedido a un hombre de bien. Pero, desde luego, no te voy a guardar un amargo rencor, aun habiéndome antes afligido, porque no por rebaños de ovejas ni por riquezas te encolerizaste, presa del resentimiento, sino por un compañero. Y espero de veras que también con otro contiendas tú en mi defensa, si algún día se diera ocasión semejante.»

${ }^{48}$ II $146-54$.
} 
desaparición de Heracles y elogia su valía, recordando las hazañas que llevó a cabo con su padre Dáscilo al someter a los pueblos colindantes ${ }^{49}$. Bien pronto aparecen nuevas referencias, al topar los argonautas con compañeros de armas de Heracles en la guerra contra las Amazonas: pasado el río Calícoro los argonautas hallan y honran la tumba de Esténelo el actórida y, antes de llegar al río Halis, tropiezan con otros camaradas de Heracles, que se presentan ante los argonautas para unirse a la expedición; así, tanto la geografía como el hallazgo de estos antiguos compañeros del héroe le sirven al poeta para introducir el mito de Hipólita y las Amazonas ${ }^{50}$. También en Ea Apolonio hace mención de Heracles, al apostillar que sólo él hubiera podido enfrentarse a la lanza de Eetes, y ningún otro de los argonautas ${ }^{51}$. Toda esta red de alusiones culmina en el libro cuarto, concretamente en el pasaje del desierto de Libia, cuando los argonautas, por cargar a hombros con la nave, sufren una sed atroz y topan con las Ninfas Hespérides; allí Orfeo implora ayuda en nombre de todos y la ninfa Egle responde recordando cómo Heracles, en su paso demoledor por allí, hizo nacer un manantial abriendo una hendidura en una roca, para beber hasta el hartazgo. Apenas lo escuchan, los héroes se lanzan eufóricos por la dirección que les indica y aplacan su sed (IV 1457-60):

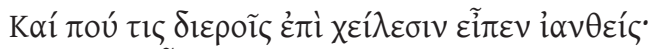

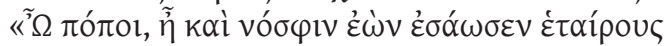

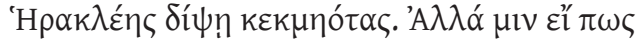

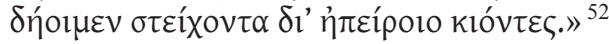

Aunque la búsqueda sea vana, el recuerdo del compañero abandonado no lo es, en la medida en que con su recurrencia reafirma el sentimiento de unión y comunidad en el grupo y, tocante a la unidad temática, hace de Heracles un motivo destacado a lo largo de la obra ${ }^{53}$.

Junto con ésta, la figura de Idas es la más representativa por las contiendas que provocan su orgullo, su enardecimiento y sus fanfarronadas, aunque, a diferencia de Heracles, sus bravatas tendrán poca o ninguna influencia sobre la expedición y lo definen como un personaje anacrónico, ridículo e irreflexivo, ya desde el comienzo ${ }^{54}$. Apenas convocada la expedición, Jasón se muestra decaído y ensimismado, reflexionando para sus adentros sobre la incipiente aventura. En cuanto se percata de ello, Idas trata de animarlo, pero pronto comienza a vanagloriarse y a lanzar bravuconadas, llegando a hacer comentarios impíos sobre Zeus (I 466) o cualquier dios que les haga frente (I 470). Al escuchar tales palabras, todos alzan la voz e Idmón

\footnotetext{
${ }^{49}$ II 771-95.

${ }^{50}$ II 911-29 y $955-69$.

${ }^{51}$ III 1231-4.

52 «Y acaso alguno con los labios húmedos dijo regocijándose: ‘¡ay, seguro que, aun estando lejos, Heracles ha salvado a sus compañeros, que de sed agonizaban! ¡Ojalá de algún modo pudiéramos en su marcha encontrarlo, mientras atravesamos esta tierra!'» El comentario colectivo en boca de uno es un procedimiento ya homérico (Il. II 271-6). Cfr. Livrea (1973: 411).

${ }^{53}$ Sobre Heracles $c f r$. Valverde (1988: 137). Para la escena del desierto de Libia, $c f r$. IV 1381-484.

${ }^{54}$ Cfr. Fränkel (1960).
} 
comienza a reprenderle, tachándolo de impío y soberbio y aduciendo un exemplum mitológico: el caso de Oto y Efialtes. El fanfarrón de Idas, en vez de echarse atrás, se burla de su compañero, menosprecia su capacidad adivinatoria y llega incluso a amenazarlo. La tensión y violencia de la escena alcanzan aquí (sin haber comenzado aún la travesía) uno de los puntos culminantes del poema: en este instante decisivo, cuando ya la riña bien pudiera haber llegado a mayores (I 492), intervienen todos los compañeros y el propio Jasón en persona, poniendo fin a la disputa (I 493-4); la tripulación restituye la concordia, malograda tan sólo por Idas, y Orfeo lo ratifica con un canto cosmogónico, perfectamente introducido en la escena, en el que se narra el devenir del universo desde el Caos hasta un orden estable y venidero, a partir de la discordia. El poeta se detiene en señalar hasta qué punto todos quedan embelesados por el hechizo de la lira de Orfeo, inmóviles y calmos, apenas balanceando en silencio sus cabezas, en contraste con la violencia y el apasionamiento de la reyerta; frente a un Idas valentón, petulante e impío, los héroes recuperan el sosiego y la concordia y vierten libaciones en honor de Zeus ${ }^{55}$.

Junto con esta escena, los altercados más representativos de Idas tienen lugar en Ea. Detenida en un venero, la compañía celebra una asamblea para decidir el modo de arrostrar las pruebas de Eetes. Argos -el hijo de Frixo- propone pedir ayuda a Medea y los dioses dan su aprobación con una señal, de la que Mopso deduce que, tal como predijo Fineo, la salvación estará en Afrodita, esto es, en el amor de Medea $^{56}$. La propuesta es aprobada por todos, salvo Idas que, indignado, les reprocha que parezcan mujeres, ocupando en observar aves y seducir vírgenes el tiempo que habrían de dedicar a la guerra ${ }^{57}$. La respuesta de sus camaradas ya no es un discurso, ni un reproche, ni una palabra siquiera, tan sólo un rumor quedo tras el cual Jasón, haciendo caso omiso de sus denuestos, decide seguir la disposición adoptada, «porque eso a todos place» (III 568) ${ }^{58}$. En los episodios que siguen las intervenciones de este héroe extemporáneo son una muestra de fracaso y frustración mal cuajados: cuando Jasón regresa de ver a Medea, Idas se queda solo, apartado, royendo su cólera ${ }^{59}$; al final, cuando Jasón empapa su lanza con las drogas de Medea, Idas, enojado con sus compañeros y fuera de sí, la golpea desesperadamente con su lanza, pero ésta rebota "como un martillo en un yunque» (III 1254): el resto de los héroes vociferan de alegría, e Idas resulta fracasado, apartado y humillado ${ }^{60}$. Como conclusión se puede advertir un dato palmario: a partir de esta intervención Idas no volverá a aparecer jamás en todo el poema; tal como se perdió Heracles, se pierde también Idas; paulatinamente había ido cediendo terreno, malogrando sus fuerzas, hallándose aislado, fuera de lugar, incapaz de comprender y aún menos de compartir la conciencia e ideales de sus compañeros. Los héroes arcaicos, representados en la figura de Heracles e Idas, habían fracasado; venció Jasón, venció el grupo, y con él la concordia.

\footnotetext{
${ }_{55}^{55}$ Toda la escena en I 460-518. Sobre la figura de Orfeo en la leyenda argonáutica, $c f$. Valverde (1993).

${ }^{56}$ III 524-40.

${ }^{57}$ III 556-64.

${ }^{58}$ III 564-71.

${ }^{59}$ III 1169-70.

${ }^{60}$ III 1252-5.
} 


\section{REAFIRMACIÓN DE LA CONCORDIA}

Junto con las contiendas y la desaparición de los héroes más problemáticos, se advierte un proceso paralelo, aunque menor, de afirmación de la homónoia: la acogida de nuevos compañeros y su integración en la tripulación, sin que se produzca jamás ningún incidente por ello. En el contexto del poema es plenamente significativa la mención, durante la escala en Lemnos, a que Atalanta quisiera unirse a la expedición pero Jasón no se lo permitiera, por si la presencia de una mujer causara querellas entre los héroes: de nuevo el tema de la homónoia como fundamento y condición indispensable de la comunidad humana, y de nuevo Jasón como garante de la misma ${ }^{61}$. Si Atalanta no es acogida, sí lo es en cambio Dáscilo, el hijo del rey Lico, a quien su padre ordena que acompañe a los argonautas para que encuentren en su viaje "gentes hospitalarias a lo largo del mar, hasta la boca del propio Termodonte» (II 804-5) ${ }^{62}$. También son acogidos Deileón, Autólico y Flogio, tres antiguos compañeros de armas de Heracles que los argonautas encuentran camino de la Cólquide y que, como Lico, no cumplen en la obra más función que la de unirse a la expedición ${ }^{63}$. Precisamente por ello son los cuatro hijos de Frixo los acompañantes más notables e integrados con que topan los argonautas en su periplo, en parte gracias al parentesco común que pronto revela Jasón (II 1160). De ellos, Melas y Citisoro sólo aparecen citados en el encuentro de ambos grupos en la isla de Ares; Frontis interviene en dos papeles, aunque no sean muy lucidos, más adelante $^{64}$. A diferencia de ellos, Argos goza de una importancia primordial en el poema, superior a la de sus hermanos y a la de la mayoría de los expedicionarios, con los que colabora generosamente: es él quien se persona ante los héroes y presenta a sus hermanos, quien guía a los argonautas hasta el Fasis, quien aconseja anclar la nave en una ribera; es él quien introduce a los héroes en el palacio de Eetes, quien toma parte destacada en los sucesos de la Cólquide -sugiriendo, por ejemplo, pedir ayuda a Medea- y quien propone, en suma, la nueva ruta de regreso, evitando ya el paso de las Simplégades ${ }^{65}$.

${ }^{61}$ I 771-3. En efecto, Atalanta, presente en la caza del jabalí de Calidón y los juegos en honor de Pelias (Apolodoro, I 8, 2 y III 13, 3 respectivamente), participaba también según algunas tradiciones en esta expedición y, de hecho, aparece como argonauta en las listas de Diodoro (IV 41) y Apolodoro (I 9, 6). Como puede observarse, tales fuentes son tardías; tal vez la presente mención de Apolonio puede estar ya haciéndose eco de esta tradición -cfr. Vian (1974b: 86, n. 1)-, pero Levin (1971: 68, n. 2) señala que ni Apolonio ni los escolios dan noticia alguna sobre esta variante en el mito. Sobre las variaciones en la nómina de argonautas y sus fuentes, $c f r$. Ruiz de Elvira (1982: 275-6), Llinares (1987: 18 y ss.) y Moreau (1994: 63, n. 16).

${ }^{62}$ Toda la escena, II 752-814. Cfr. Levin (1971: 188, n. 3). Dáscilo volverá a aparecer una vez, cuando se anuncia su vuelta a casa en IV 298.

${ }^{63}$ II $955-64$.

${ }^{64}$ IV 72-4 y 80. Ambos grupos se topan en II 1094 y ss.

${ }^{65}$ II 1122 y ss., 1260-1, 1281 y ss.; III 317 y ss., 475 y ss., 521 y ss., 913 y ss., 1199-1200; IV 122 y 256 y ss. Es de advertir que, de los cuatro hermanos, Argos es el primogénito, cfr. III 319. 


\section{CONCLUSIONES}

La concordia, pues, es sin duda uno de los motivos fundamentales en las Argonáuticas, tanto por la diversidad de sus manifestaciones como por su constante recurrencia a lo largo de toda la obra. De hecho, si bien pudiera argüirse, con Vian ${ }^{66}$, que la homónoia parece estar más visible en los tres primeros libros, en el cuarto no deja en cualquier caso de advertirse; más bien da la impresión de que, para mantener su continuidad, el motivo evoluciona acomodándose al cambio de circunstancias humanas y materiales en la expedición: una vez perdido Heracles, arrinconado Idas, acogidos los hijos de Frixo y logrado ya el vellocino, queda aún retornar sanos y salvos para concluir con éxito la empresa. En este contexto, en el libro cuarto, el canto del regreso, la concordia continúa bien presente: por un lado, como reflejo de la unión de los argonautas ante el peligro o la adversidad, y así tan a menudo frente a Eetes y sus hombres, así al dar muerte a Canto, así en su extravío por el desierto de Libia -no es vano que sea en Libia, precisamente en uno de los momentos más difíciles para los argonautas, donde todos colaboren cargando con el navío y Jasón confíe decididamente en su compañía para salir de las dificultades ${ }^{67}$; por otra parte, de la concordia da buena muestra también la alegría de volver y haber cumplido con la labor emprendida, tanto en competiciones amistosas lanzando discos o recogiendo agua, como en las bromas con las esclavas feacias o en la erección final de altares a Atenea y Apolo ${ }^{68}$. La concordia en el libro cuarto aparece como un logro ya acabado y ostensible de la expedición argonáutica.

Tocante a su función literaria, el motivo de la homónoia contribuye sin duda a la unidad temática de toda la obra, ejerciendo de vínculo constante y aludiendo o entreverándose con otros temas recurrentes, como la figura de Heracles o la propia compañía de argonautas ${ }^{69}$. A este respecto se puede añadir que la participación de un elenco tal de personajes permite al poeta modelar caracteres y tipos humanos de muy variado relieve, demostrándose así, una vez más, el interés de Apolonio por el comportamiento y la psicología del hombre, interés tan notorio en la persona de Jasón o Medea. En último término, pues, las relaciones interpersonales constituyen un vasto motivo en las Argonáuticas $^{70}$, y en ellas, por lo que toca a la constitución

\footnotetext{
${ }^{66}$ Vian (1974a: 349).

${ }^{67}$ Sumariamente: los argonautas huyen de Eetes en Ea (190 y ss.) y de sus hombres (495 y ss.), tomando una nueva ruta de regreso que Argos les propone (257-97); caen sobre un navío enemigo y matan a sus tripulantes (484 y ss.); se aprestan para el combate mientras Jasón y Medea celebran sus bodas (1000); cargan con su navío a hombros por el desierto (1382 y ss.) y terminan con Canto, por haber dado muerte a un compañero (1485 y ss.). Adviértase, además, en este libro cuarto, cuán representativo es el discurso de Jasón en Libia (1333-6), en paralelismo y correlación evidentes con los pronunciados en I 336-40 y II 171-5.

${ }^{68} C f r$. IV 851 y ss; 1767 y ss.; 1725 y ss.; 1690 y ss. y 1714 y ss. (Cfr. también supra n. 25, 27 y 38) De un modo u otro pueden añadirse, como visión de conjunto, todos los pasajes del libro cuarto citados en el punto segundo a propósito de la colaboración y el sentir compartido de los argonautas, o el antedicho recuerdo de Heracles en Libia, que culmina toda las evocaciones que hay a lo largo de la obra.

${ }^{69}$ Sobre los núcleos temáticos del poema y su unidad, $c f r$. Valverde (1988).

${ }^{70}$ Así Jackson (1992: 155): «The poem is concerned with man's inter-relationship with both his fellow- man and with the gods.»
} 
política de la comunidad humana, la concordia se revela como una de las virtudes paradigmáticas $^{71}$.

Sin embargo, tal vez la presencia de la concordia en las Argonáuticas tenga su fundamento en motivaciones no meramente literarias y responda también a razones político-religiosas y filosóficas. En efecto, en los últimos años diversos estudios, debidos, entre otros, a Anatole Mori y Richard Hunter, han puesto de manifiesto las múltiples relaciones existentes entre la obra de Apolonio de Rodas y ciertos aspectos históricos del siglo III a. C., entre ellos la praxis política de la monarquía ptolemaica ${ }^{72}$. A este respecto es preciso reseñar aquí que Hunter ha advertido precisamente cómo el empeño que los argonautas ponen en la concordia ( «social harmony») y su reiteración en la obra evidencian un culto helenístico contemporáneo ${ }^{73}$. En cuanto a la filosofía, las relaciones entre la amistad y diversos aspectos de la organización sociopolítica (justicia, igualdad, concordia) constituyeron entre los s. VI y IV a. C. una fertilísima materia de reflexión, desarrollada por Pitágoras, la sofística, Platón y Aristóteles ${ }^{74}$. En el caso de las Argonáuticas, el motivo de la homónoia testimonia también cierta inclinación moral perceptible en la literatura de su tiempo y especialmente el influjo de la filosofía en la poesía helenística ${ }^{75}$. La propia A. Mori ha destacado cómo la reconciliación entre Jasón y Telamón, y en general el proceder de Apolonio con el motivo de la ira, ejemplifica bien los postulados aristotélicos al respecto, cotejando tales pasajes con textos paralelos de la Ilíada y la Odisea; también R. Hunter señaló la relación entre el tema de la cólera de Jasón e importantes capítulos de Ética Nicomaquea (2.1108a4-9 y $4.1125 \mathrm{~b} 26-26 \mathrm{~b} 10)^{76}$. No es de extrañar, pues, que diversos aspectos de las Argonáuticas puedan reflejar también las tesis de Aristóteles sobre la homónoia, especialmente las contenidas en los libros noveno de la Ética Nicomaquea (1167a-b) y séptimo de la Ética Eudemia (1241a).

${ }^{71}$ Desde la teoría política de los siglos V y IV a. C. hasta el tiempo de la Segunda Sofística, a través del mundo helenístico y la política en el Imperio Romano, el concepto de concordia varía, se renueva y evoluciona. Sobre ello, $c f$ r. el artículo de Daverio (2007), en un volumen colectivo dedicado a la concordia y la paz en la Antigüedad, así como la obra de Kramer (1915), Ferguson (1958: 118-32) y Moulakis (1973), las consideraciones de Bravo (1973, esp. pp. 84-6) a propósito de Dión de Prusa y el trabajo de Kamtekar (2004) sobre Platón. Cfr. también la obra de Hill (1992), a la que no hemos podido acceder. En cuanto a la concordia en Roma, $c f r$. el repertorio de Montero, S. y Perea, S. (1999). Desde la Roma imperial la concordia se trasmite al pensamiento cristiano en autores como Prudencio, Tertuliano o San Agustín. Cfr. Moreno (1994: 144, n. 2).

${ }^{72}$ Véase Hunter (1993: 152-69, «The Argonautica and its Ptolemaic context») y (1995). Tocante a los trabajos de Mori, cfr. el de (2001) y su The politics of Apollonius Rhodius'Argonautica (2008), al que, sin embargo, hemos podido acceder ya durante la corrección de pruebas. En lo que respecta a la concordia, a la que Mori concede una gran importancia (cfr. ibid. Index, s.v. homonoia), véase el amplio análisis del capítulo tercero, «Strife and restraint among the Argonauts», pp. 52-90.

${ }^{73}$ Hunter (1995: 19 n. 28), cit. por Mori (2001: 89). Sobre la cuestión, cfr. también Thériault (1996a) y (1996b).

${ }^{74}$ Cfr. López Salvá (1994).

${ }^{75}$ Mori (2005: 214-5 y esp. 217-27). En cuanto a la relación entre las Argonáuticas y la filosofía, Klein (1983) y Williams (1996) observaron en ciertos aspectos de la obra alusiones a doctrinas escépticas y estoicas, respectivamente.

${ }^{76}$ Cfr. Mori (2005: 210-7, 227-33 y, con referencia a Hunter, p. 230 n. 78) y Hunter (2002, 145-6). 
La concordia aristotélica y argonáutica media en los ámbitos ético y político, constituyendo una suerte de amistad que trasciende a la relación personal y se convierte en un valor eminentemente colectivo que preserva la comunidad de la stásis ${ }^{77}$; de ello Apolonio da cuenta en la conciencia de comunidad y el continuo afán por evitar la disensión y mantener la concordia, motivos reiterados a lo largo de la obra, especialmente en los momentos más delicados ${ }^{78}$. La homónoia es una amistad política, una amistad entre ciudadanos que supera la mera identidad de opiniones (homodóxia) ${ }^{79}$ y que de hecho podría darse entre personas que no se conozcan previamente, tal como sucede en la acogida de Dáscilo, Deileón, Autólico, Flogio o los hijos de Frixo. En calidad de garante de la comunidad, precisa para su plena realización de hombres buenos y conscientes del sumo valor del bien común como base de toda comunidad política: de ello pueden dar muestra las numerosas ocasiones en que Jasón recuerda el carácter colectivo de su empresa. De igual manera, requiere hombres capaces de desear lo justo, lo ventajoso y lo conveniente, y ganosos, en fin, de lograr sus objetivos en común: así ocurre también en Apolonio, tanto en las deliberaciones como en la constante actuación colectiva de la expedición. Como valor destacadamente político, la concordia aristotélica exige de los ciudadanos tres condiciones que los argonautas se afanan por cumplir a lo largo de la obra: el consenso sobre los asuntos de interés general y capital importancia, la avenencia a la hora de tomar las decisiones y la voluntad colectiva de llevar a término cuanto se ha acordado en común ${ }^{80}$.

Al engarzarse philía y koinonía, la concordia en Aristóteles se erige en una amistad cívica que otorga a la comunidad un cierto grado de unión, posibilita a los ciudadanos la adopción de decisiones libres y razonadas y favorece el buen gobierno, los regímenes mixtos de oligarquía y democracia y especialmente la promoción de ésta última, tan destacada en la política de los argonautas ${ }^{81}$.

Como símbolo de este leitmotiv a lo largo de la obra, los argonautas, tras dejar atrás a Heracles, franquear el paso de las Simplégades y superar airosamente la peîra de Jasón ${ }^{82}$, cantan, danzan, juran socorrerse los unos a los otros con espíritu concorde y, en una escena emblemática del poema, elevan un altar a la Homónoia (II 717-9):

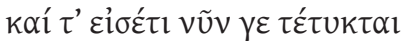

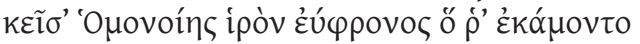

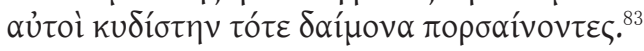

\footnotetext{
${ }^{77}$ Sobre la stasis, cfr. la obra de Kalimtzis (2000).

${ }^{78}$ Et. Nic. 1155a 3. Cfr. Klonoski (1996) y Bravo (1973: 85-6).

${ }^{79}$ Cfr. al respecto Et. Nic. 1167a y Fraisse (1974: 250): «L'homonoia ne se confond pas avec l'identité d'opinions, ou homodoxia».

${ }^{80}$ Para todo ello, cfr. Et. Nic. 1167a-b y Et. Eud. 1241 .

${ }^{81}$ Klonoski (1996).

${ }^{82}$ Fränkel (1968: 229) y Vian (1974b: 124). Para este aítion, cfr. el estudio de Valverde (1989: 200-1).

${ }^{83}$ «Y todavía hoy está erigido allí un santuario de la benévola Concordia, el que levantaron ellos mismos en aquel tiempo, en alabanza de la más gloriosa divinidad.»
} 


\section{REFERENCIAS BiBLIOGRÁFICAS}

Bravo G., A. (1973), «Notas sobre el tema de la concordia en Dión de Prusa», Habis, 4: 81-92. Brioso S., M. (2003³), Las Argonáuticas. Madrid.

Carspecken, J. F. (1952), «Apollonius Rhodius and the Homeric Epic», YClS, 13: 33-143.

Clauss, J. J. (1993), The best of the Argonauts: the redefinition of the epic hero in book 1 of Apollonius's Argonautica. California.

DAVERIo R., G. (2007), «La concordia: tema culturale, obiettivo politico e virtù civica», en Daverio R., G. (ed.), Tra concordia e pace. Parole e valori della Grecia antica, Milano: 3-38.

Fraisse, J. C. (1944), Philia. La notion de l'amitié dans la philosophie antique. Paris.

García Gual, C. (1975), El viaje de los argonautas. Madrid. Reimpr. (2004), Madrid.

Green, P. (2007), The Argonautika by Apollonios Rhodios. California.

FERguson, J. (1958), Moral values in the Ancient World. London.

FräNKel, H. (1960), «Ein Don Quijote unter den Argonauten des Apollonios», MH 17: 1-20.

- (1961), Argonautika. Recognovit brevique adnotatione critica instruxit Hermann Fränkel. Oxford.

- (1968), Noten zu den Argonautika des Apollonios. München.

HiLl, S. R. (1992), Concordia: on the roots of European thought: comparative studies in Vedic and Greek ideas. London.

Hunter, R. (1988), «Short on Heroics: Jason in the Argonautica», CQ 38: 436-53.

- (1993), The Argonautica of Apollonius: literary studies. Cambridge.

- (1995), «The Divine and Human Map of the "Argonautica”», SyllClass, 6: 13-28.

- (2000), «Le Argonautiche di Apollonio Rhodio e la tradizione epica», en M. Fantuzzi y R. Hunter (ed.), Muse e Modelli. La poesia ellenistica da Alessandro Magno ad Augusto. Roma: 121-75.

JACKSON, S. (1992), «Apollonius' Jason: Human being in an epic scenario», G\&R XXXIX. 2: 155-162. Reimpr. (2004) en Mainly Apollonius: collected studies, Amsterdam: 1-8.

Kalimtzis, K. (2000), Aristotle on Political Enmity and Disease: An Inquiry into Stasis. Albany.

KamtekAR, R. (2004), «What's the good of agreeing? Homonoia in the Platonic politics», OSAP, 24: 131-170.

KleIN, T. M. (1983), «Apollonius' Jason: Hero and Scoundrel», QUCC, 13: 115-26.

Klonoski, R. J. (1996), «Homonoia in Aristotle's Ethics and Politics», HPT, 17/3: 313-325.

Knight, V. (1995), The renewal of Epic. Responses to Homer in the Argonautica of Apollonius. Leiden.

Kramer, H. (1915), Quid valeat Ónóvora in litteris graecis. Göttingen.

Montero, S. y Perea, S. (1999), Romana Religio / Religio Romanorum. Diccionario Bibliográfico de Religión Romana. 'Ilu. Rev. Cienc. Relig., Anejos, 3. Madrid.

Moreau, A. (1994), Le mythe de Jason et Médée. Le va-nu-pied et la sorcière. París.

Levin, D. N. (1971), Apollonius' Argonautica re-examined: I, The neglected first and second books. Leiden.

Livrea, E. (1973), Argonauticon liber quartus. Edizione, introduzione, testo critico, traduzione e commento a cura di Enrico Livrea. Firenze.

LlinARES G., M. (1987), «Mitología e iniciaciones: el problema de los argonautas», Gerión, 5: 15-42. 
López SAlVÁ, M. (1994), «Relación de amistad y justicia en el pensamiento político-filosófico griego (s. VI-IV a.C.)», en R. M. Aguilar, M. López Salvá e I. Rodríguez Alfageme (ed.), Xর́pıৎ $\delta \imath \delta \alpha \sigma \kappa \alpha \lambda i ́ \alpha \varsigma$. Homenaje a Luis Gil, Madrid: 559-77.

Montero, S. y Perea, S. (1999), Romana Religio / Religio Romanorum. Diccionario Bibliográfico de Religión Romana. 'Ilu. Rev. Cienc. Relig., Anejos, 3. Madrid.

Mooney, G. W. (1912), The Argonautica of Apollonius Rhodius, edited with introduction and commentary by George W. Mooney. Dublin. Reimp. en Amsterdam, 1964.

Moreau, A. (1994), Le mythe de Jason et Médée. Le va-nu-pied et la sorcière. Paris.

Moreno, J. L. (1994), «Concordia y paz en Aurelio Prudencio», AHIg, 3: 143-161.

Mori, A. (2001), «Personal Favor and Public Influence: Arete, Arsinoë II, and the Argonautica», OT, 16/1: 85-106.

- (2005), «Jason's reconciliation with Telamon: a moral exemplar in Apollonius' Argonautica (1.1126-1344) », AJP, 126: 209-236.

- (2008), The Politics of Apollonius Rhodius'Argonautica. Cambridge.

Moulakis, A. (1973), Homonoia: Eintracht und die Entwicklung eines politischen Bewussteins. München.

Paduano, G. y Fusillo, M. $\left(2000^{12}\right)$, Le Argonautiche, traduzione di Guido Paduano, introduzione e commento di Guido Paduano e Massimo Fusillo. Milano.

Palombi, M. G. (1985), «Eracle e Ila nelle Argonautiche di Apollonio Rodio», SCO, 35: 71-92.

Pérez, L., M. (1991), Las Argonáuticas. Madrid.

Phinney, E. St. Jr. (1963), Apollonius Rhodius. Michigan. (Microfilm.)

Rieu, E. V. (1959), The Voyage of the Argo. London.

Ruiz de Elvira, A. (1982), Mitología Clásica. Madrid.

Seaton, R. C. (1967), The Argonautica, with an English translation by R. C. Seaton. London.

THÉRIAUlt, G. (1996a), Le culte d'Homonoia dans les cités grecques. Québec-Lyon.

- (1996b) «L' apparition du culte d'Homonoia», LEC, 64: 127-150.

VALVERDE S., M. (1988), «En torno a la estructura y contenido de las Argonáuticas de Apolonio de Rodas», Myrtia, 3: 119-156.

- (1989), El aition en las Argonáuticas de Apolonio de Rodas: estudio literario. Murcia.

— (1993), «Orfeo en la leyenda argonáutica», EClas, 35: 7-16.

- (1996), Argonáuticas. Madrid.

Vian, F. (1974a), Reseña de Levin (1971), Gnomon, 46.

Vian, F. y Delage, É. - (1974b), Argonautiques. Tome I, Chants I-II. Texte établi et commenté par Francis Vian et traduit par Émile Delage. Paris.

- (1980), Argonautiques, Tome II, Chant III. Texte établi et commenté... Paris.

- (1981), Argonautiques, Tome III, Chant IV. Texte établi et commenté par Francis Vian et traduit par Émile Delage et Francis Vian. Paris.

Wilamowitz, U. v. (1924), Hellenistiche Dichtung in der Zeit des Kallimachos. Vol. II. Berlin. Williams, M. F. (1996), «Stoicism and the Character of Jason in the Argonautica of Apollonius Rhodius», Scholia, 5: 17-41. 